\title{
Effect of Large Negative Phase of Blast Loading on Structural Response of RC Elements
}

\author{
Zubair Iman Syed ${ }^{1, a}$, Priyan Mendis ${ }^{2}$ and Shaikh Atikur Rahman ${ }^{3}$ \\ ${ }^{1}$ Department of Civil Engineering, Abu Dhabi University, UAE \\ ${ }^{2}$ Department of Infrastructure Engineering, The University of Melbourne, Australia \\ ${ }^{3}$ Department of Civil Engineering, Universiti Teknologi PETRONAS, Malaysia
}

\begin{abstract}
Structural response of reinforced concrete (RC) elements for analysis and design are often obtained using the positive phase of the blast pressure curve disregarding the negative phase assuming insignificant contribution from the negative phase of the loading. Although, some insight on the effect of negative phase of blast pressure based on elastic single-degree-offreedom (SDOF) analysis was presented before, the influence of negative phase on different types of resistance functions of SDOF models and on realistic finite element analysis has not been explored. In this study, the effects of inclusion of pulse negative phase on structural response of RC elements from SDOF analysis and from more detailed finite element analysis have been investigated. Investigation of SDOF part has been conducted using MATLAB code that utilizes non-linear resistance functions of SDOF model. Detailed numerical investigation using finite element code DIANA was conducted on the significance of the negative phase on structural response. In the FE model, different support stiffness was used to explore the effect of support stiffness on the structural response due to blast negative phase. Results from SDOF and FE analyses present specific situations where the effect of large negative phase was found to be significant on the structural response of RC elements.
\end{abstract}

\section{Introduction}

Due to the high degree of uncertainty involved in blast load prediction, complex time consuming detailed structural analysis is often not justified. Single-degree-of-freedom (SDOF) analysis has the potential of giving a good prediction of final response of the critical point of a structure. All commonly used design manuals for blast loading like PDC-TR 08-07 [1] and UFC 3-340-02 [2], and widely used design tools such as Single-Degree-of-Freedom Blast Effects Design Spreadsheets (SBEDS) [3] and Facility and Component Explosive Damage Assessment Program (FACEDAP) [4], are based on the SDOF response calculation of structural components. Since initiation of using SDOF approach for structural response calculation for impulsive loads, significant advances have been achieved in the application of SDOF models, hence the use of SDOF models has also increased significantly in area of protective design.

Depending on the location of blast and type of explosive, the negative phase of a blast pressure curve can be significant and can contribute to the damage of RC elements. Literature related to the

\footnotetext{
${ }^{a}$ Corresponding author : zubair.syed@adu.ac.ae
} 
development of the damage assessment tool FACEDAP has acknowledged the fact that the negative phase can be "in-phase" with the component response. In CEDAW [1], it has been indicated that the negative phase loading only affects component response when scaled pressure is high relative to scaled impulse, which corresponds to cases where the positive phase blast load durations are relatively short compared to the component response time.

In this study, the effect of inclusion of pulse negative phase on structural response of RC elements obtained using SDOF models has been investigated. Non-linear transient analysis was also conducted to explore the significance of the negative phase on structural response using finite element code DIANA [5]. Different support stiffness was used for the FE model to explore the effect of support stiffness on the structural response due to blast load with large negative phase. Results from both SDOF model and FE analysis are presented to establish the effect of large negative on structural response of $\mathrm{RC}$ elements.

\section{Blast Pressure Idealisation and Negative Phase}

Selection of appropriate blast loading is critical for realistic and reliable structural response of reinforced concrete elements under blast loading. Chemical investigations and experimental data have shown that the evolution of blast load pressure $(\mathrm{P})$ with time $(\mathrm{t})$ can be simulated more accurately by a quasi-exponential distribution [6] as a modified Friedlander equation as given below:

$$
p(t)=p_{s o}\left(1-\frac{t}{t_{d}}\right) \exp \left\{-\frac{\alpha t}{t_{d}}\right\}
$$

where $\alpha$ is the dimensionless waveform parameter also known as decay coefficient. The parameter alpha $(\alpha)$ determines the extent of negative phase in the exponential distribution of Equation (1). If $\alpha$ is smaller than one, there is a larger negative phase in the pressure curve, while if $\alpha$ is larger than one, the negative phase becomes less significant. The blast pulse profile for different values of waveform parameter alpha $(\alpha)$ in Friedlander equation is shown in Figure 1.

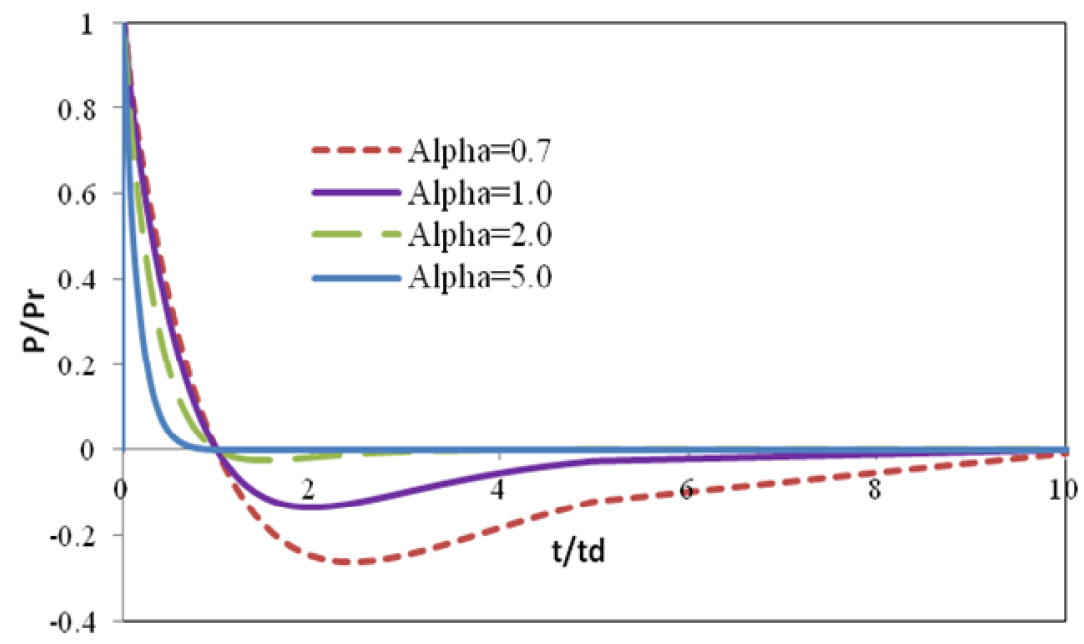

Figure 1. Blast load profile obtained using Friedlander equation with different values of waveform parameter $(\alpha)$.

In this figure, the ratio between pressure at a given time $(\mathrm{P})$ and the peak pressure $\left(\mathrm{P}_{\mathrm{r}}\right)$ has been plotted against the ratio of corresponding time $(t)$ to the positive duration value $\left(t_{d}\right)$. The blast pulse profile presented by the Friedlander equation with an $\alpha$ value of unity has been found to match well 
with some experimental results [7]. However, depending on various factors such as change weight, scaled distance, type of blast and other factors, the blast pressure can have a negative phase much higher than the phase represented by the $\alpha$ value of one. In those situations, to idealise the blast pulse profile, $\alpha$ values smaller than unity are required. Values of $\alpha$ higher than unity correspond to smaller negative pressure, and values above five produce virtually zero negative phase. The duration of the negative phase is usually double that of the positive phase [6].

\section{Single Degree of Freedom Models}

The equivalent SDOF method, which is widely used in protective design practices, has been used in this study to convert the real reinforced concrete elements into equivalent SDOF models. The transformation factors that are applied to the distributed values to calculate the equivalent lumped values are a function of the distribution of mass and loading over the element and the shape function of the deflected shape [8].

Numerical time integration procedures were implemented in MATLAB [9] code to obtain solutions for SDOF models with advanced non-linear resistance functions. Non-linear resistance functions were developed using the moment-curvature relationships which were constructed using material constitutive models of concrete and reinforcement bars. Numerical approximation method proposed by Newmark with modified Newton-Raphson iteration was adopted in the MATLAB codes for dynamic response. The response of the SDOF model with non-linear resistance function was calculated using incremental time-stepping approach. Details on these steps can be found in Chopra [10]. For each load value, the corresponding maximum deflection at the mid-span was obtained by integration of the curvature along the half-length of the element. These codes were developed and verified against numerical FE results and other known experimental results. The details about the selected material models and the code verification can be found in Syed et al. [11, 12].

\section{Response of SDOF Models under Blast with Negative Phase}

Response spectra for SDOF models can readily be used for predicting the maximum response of the system. Widely referred response spectra for blast design given in UFC 3-304-2 [2] are for elasticplastic resistance functions and for idealised blast load with positive phase only. Gantes and Pnevmatikos [13] employed an elastic-perfectly plastic resistance function to compare response spectra obtained using exponential load. In the present research, response spectra were obtained for elastic-plastic hardening using exponential blast load with negative phase to mainly investigate the effect of negative phase on a realistic idealised structure. Figure 2 shows comparison of the response obtained from elastic-plastic $\left(\mathrm{K}_{\mathrm{s}}=0\right)$, elastic-plastic hardening with secondary stiffness $10 \%$ of initial stiffness $\left(\mathrm{K}_{\mathrm{s}}=0.1 \mathrm{~K}\right)$ and elastic-plastic hardening with secondary stiffness $20 \%$ of initial stiffness $\left(\mathrm{K}_{\mathrm{s}}\right.$ $=0.2 \mathrm{~K}$ ) for exponential loading. Detail on how to obtain system stiffness value for equivalent SDOF system is presented in Syed et al. [11]. The responses for various ratios of maximum response to elastic response of the system $\left(\mathrm{X}_{\max } / \mathrm{X}_{\mathrm{el}}\right)$ are presented in Figure 2 in terms of the ratios of maximum resistance to peak load $\left(\mathrm{R}_{\mathrm{m}} / \mathrm{P}\right)$. Variation between maximum responses of a SDOF model depends on the ratio of peak resistance to peak load $\left(\mathrm{R}_{\mathrm{m}} / \mathrm{P}\right)$ and the ratio of the blast duration to SDOF system period $\left(t_{d} / T\right)$. Figures 3 and 4 show the comparison of responses for from triangular and exponential load loads.

It can be observed from the response spectra of elastic-plastic hardening system that when $\mathrm{R}_{\mathrm{m}} / \mathrm{P}$ is larger (between 1 and 2), the response for exponential load is smaller compared to that obtained from triangular load. This can be explained as the exponential load decreases faster than the triangular one, and this has more influence in elastic-plastic situations than in purely elastic cases. The duration of blast loading $\left(t_{d}\right)$ usually varies within a small range of values; large values of $t_{d} / T$ correspond to small values of the fundamental period $(\mathrm{T})$, therefore, to stiff systems. Commonly used assumptions of triangular blast load can sometimes be slightly under-conservative, particularly for flexible structural systems, but can also be significantly over-conservative for stiffer structures. 


\section{MATEC Web of Conferences}

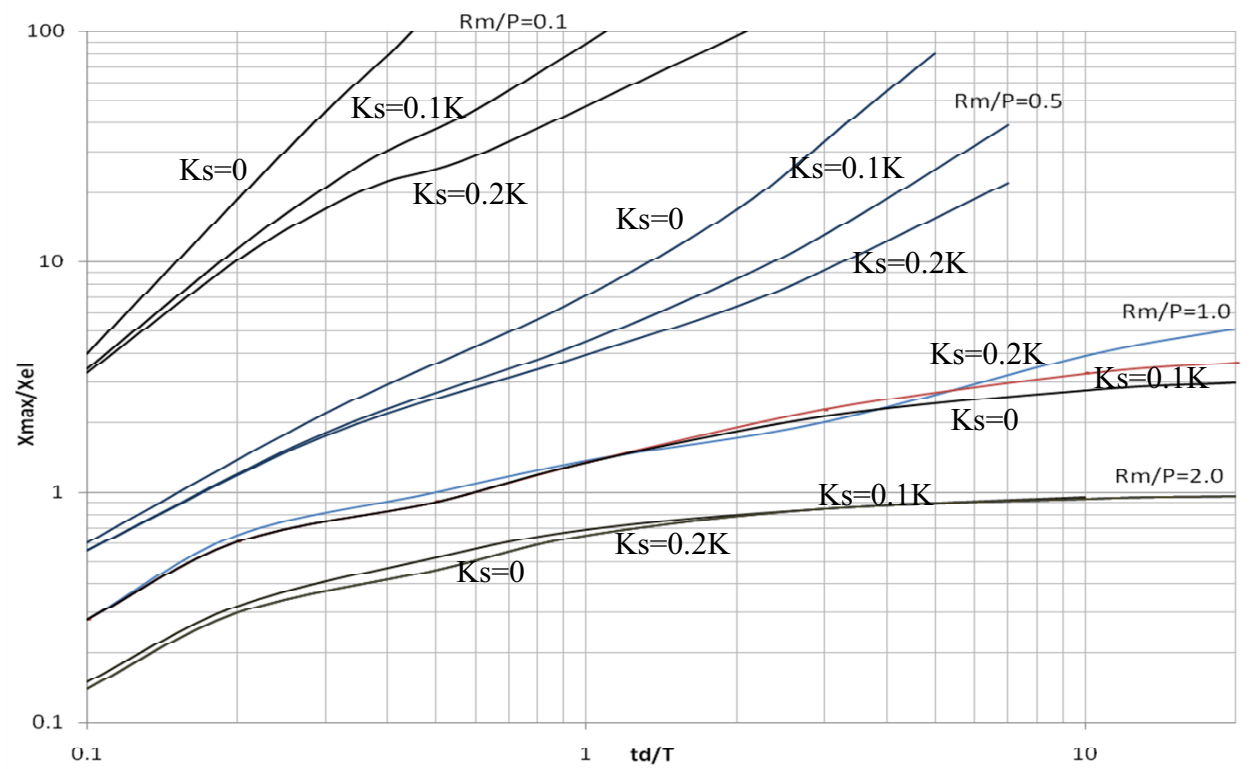

Figure 2. Response spectra for elastic-perfectly plastic and plastic hardening SDOF system under exponential loading with negative phase.

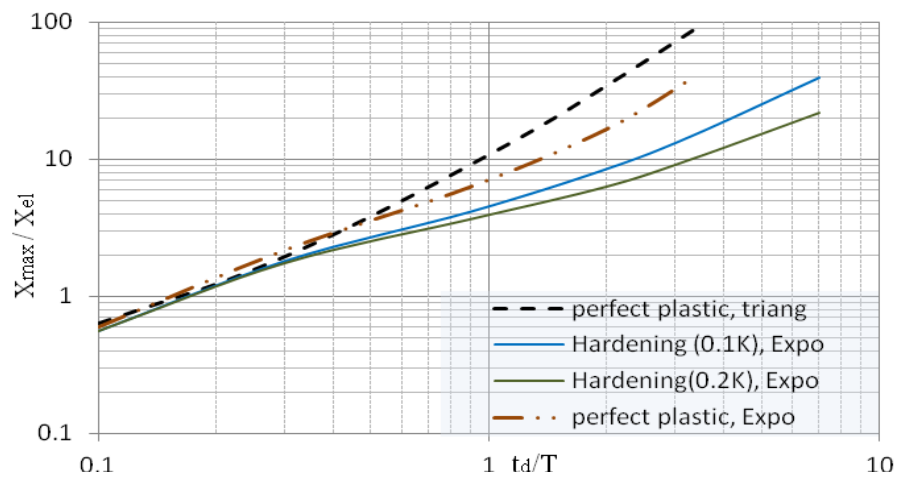

Figure 3. Comparison between response under triangular and exponential load with negative phase for $\mathrm{R}_{\mathrm{m}} / \mathrm{P}=0.5$.

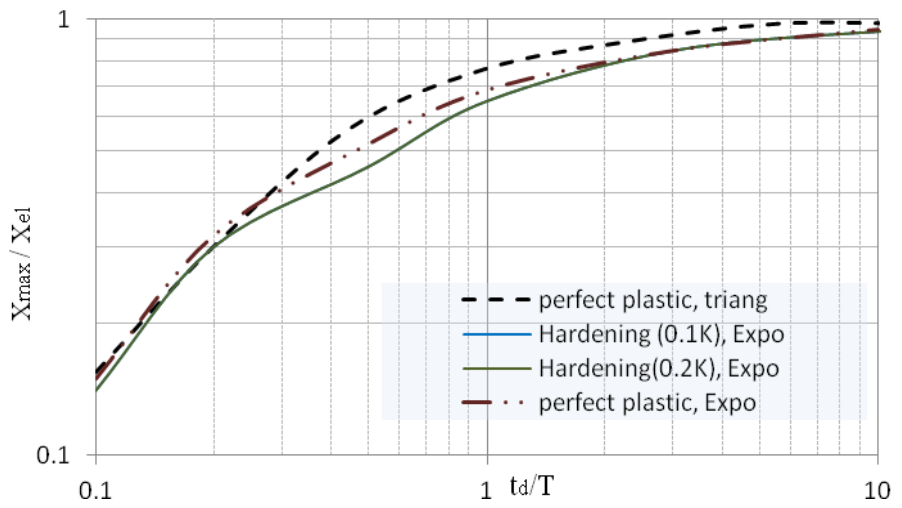

Figure 4. Comparison between response under triangular and exponential load with negative phase for $\mathrm{R}_{\mathrm{m}} / \mathrm{P}=2.0$. 
If rebound of the system occurs in a period of negative phase of the blast load, then this may lead to maximum displacement of the system due to the negative phase. Thus, the negative plastic deformations due to negative plastic forces may exceed in magnitude the positive plastic deformations caused by the larger forces of the triangular pulse.

If $t_{d} / T$ is longer than 0.5 , then the maximum deformation occurs during the pulse and the shape of loading is of great significance. If $\mathrm{t}_{\mathrm{d}} / \mathrm{T}$ is less than 0.5 , then the maximum deformation occurs during the free vibration and is mainly controlled by the time integral of the phase, independent of the shape of loading. Similar conclusions can also be found in Chopra [10] and Gantes and Pnevmatikos [13].

\section{Structural Response of RC Beam to Negative Phase}

Non-linear FE analyses were performed using FE code DIANA to explore the effect of negative phase on the overall structural response of a reinforced concrete beam for different support conditions. A normal strength reinforced concrete beam (B40-D4) tested by Magnusson and Hallgren [14] under blast load was modelled. Dimensions of the beam were 300 (W) x 160 (D) x 1500 (L) and had a static compressive strength of concrete of $43 \mathrm{MPa}$. The beam was reinforced with $5 \mathrm{H} 16 \mathrm{~mm}$ bars with yield strength of $555 \mathrm{MPa}$.

The beam was modelled using beam-elements, CL18B (a class-III beam-element from the DIANA library), based on the Mindlin-Reissner beam theory utilizing total strain-based modelling approach. In total strain-based modelling of concrete elements, the stress-strain relationship of the concrete by Thorenfeldt et al. [15] has been used for modelling the compressive behaviour. This model has been found to be in good correlation with the experimental data and has been used by a large number of researchers in the area of impact and blast loading on concrete elements [16]. Non-linear tension softening model proposed by Hordijk and in build in DIANA material library has been used in this study. A rotating axis approach has been adopted that does require an explicit value of shear retention during modelling. The constitutive model of steel reinforcement is based on the von Mises plasticity model with strain hardening. The plastic modulus of the material $\left(\mathrm{E}_{\mathrm{sh}}\right)$ is assumed to be $1.5 \%$ of its elastic modulus $\left(E_{\mathrm{s}}\right)$ as similar values is found to be used successfully in the past studies [17]. Midspan deflection-time histories obtained from finite element simulation was compared with the experimental results for verification purposes. In the FE simulation, the blast pressure on the beam was applied as a time-dependent line load.

To study the effect of negative phase, a blast load with a peak pressure of $0.25 \mathrm{MN} / \mathrm{m}$ and positive phase duration of $8 \mathrm{msec}$ was used. The negative phase of the selected load followed the modified Friedlander equation as defined previously. The response of the modelled beam was calculated with four different support spring stiffness values and also for a simply supported condition. The maximum inward and outward deflections of the mid-span for different support conditions under blast load with and without negative phase are presented in Table 1. It was found that the inclusion of negative phase reduced the inbound displacements by a small amount for some support conditions and the rebound displacements were found to increase in all the support conditions. For all types of support stiffness values, similar changes were observed. Although the less stiff support springs showed a higher displacement under blast load with and without negative phase compared to the stiffer supports, it did not demonstrate any significant higher rate of change in inbound and rebound displacements for the inclusion of the negative phase.

The responses of the beam with four types of support conditions under different peak pressures were also calculated. In all cases, the positive duration was selected as $8 \mathrm{~ms}$ and the waveform parameter or decay coefficient $(\alpha)$ of the modified Friedlander equation was selected as 0.7 . The objective of this investigation was to explore the effect of negative phase of blast pressure on the structural response under different peak pressures. Three different peak load values were selected: $0.15 \mathrm{Mn} / \mathrm{m}, 0.25 \mathrm{MN} / \mathrm{m}$ and $0.40 \mathrm{MN} / \mathrm{m}$. Maximum mid-span deflections calculated for load with negative phase for different peak pressures for different support conditions are tabulated in Table 2. 
Table 1. Maximum mid-span deflections for the beam with different support conditions under blast load with and without negative phase.

\begin{tabular}{|c|c|c|c|c|c|}
\hline \multirow{3}{*}{$\begin{array}{c}\text { Support } \\
\text { condition } \\
\text { notation }\end{array}$} & \multirow{3}{*}{$\begin{array}{c}\text { Support } \\
\text { spring-beam } \\
\text { stiffness ratio } \\
\left(\mathbf{K}_{\mathrm{sp}} / \mathbf{K}_{\mathrm{el}}\right)\end{array}$} & \multicolumn{4}{|c|}{$\begin{array}{l}\text { Maximum mid-span deflection } \\
(\mathbf{m m})\end{array}$} \\
\hline & & \multicolumn{2}{|c|}{$\begin{array}{l}\text { Blast load without negative } \\
\text { phase }\end{array}$} & \multicolumn{2}{|c|}{ Blast load with negative phase } \\
\hline & & Inbound & Rebound & Inbound & Rebound \\
\hline SP1 & 0.7 & 8.12 & -3.22 & 7.42 & -4.33 \\
\hline SP2 & 1 & 8.28 & -2.32 & 8.12 & -2.38 \\
\hline SP3 & 10 & 7.71 & -2.21 & 7.81 & -3.20 \\
\hline SP4 & 100 & 7.57 & -2.11 & 7.57 & -3.04 \\
\hline S-S & Simply supp. & 7.55 & -2.14 & 7.54 & -3.18 \\
\hline
\end{tabular}

Table 2. Summary of the responses calculated for load with negative phase for different peak pressures for different support conditions.

\begin{tabular}{|c|c|c|c|c|c|c|}
\hline \multirow{2}{*}{$\begin{array}{l}\text { Support } \\
\text { condition } \\
\text { notation }\end{array}$} & \multicolumn{2}{|c|}{ Peak load 0.15 N/m } & \multicolumn{2}{c|}{ Peak load 0.25 N/m } & \multicolumn{2}{c|}{ Peak load 0.40 MN/m } \\
\cline { 2 - 7 } & $\begin{array}{c}\text { Maximum mid-span } \\
\text { deflection (mm) }\end{array}$ & \multicolumn{2}{c|}{$\begin{array}{c}\text { Maximum mid-span } \\
\text { deflection (mm) }\end{array}$} & \multicolumn{2}{c|}{$\begin{array}{c}\text { Max mid-span deflection } \\
\text { (mm) }\end{array}$} \\
\cline { 2 - 7 } & Inbound & Rebound & Inbound & Rebound & Inbound & Rebound \\
\hline S-S & 3.70 & -3.97 & 7.54 & -4.01 & 19.20 & -4.72 \\
\hline SP2 & 3.61 & -3.96 & 8.18 & -3.78 & 17.80 & -4.75 \\
\hline SP3 & 3.73 & -3.98 & 7.88 & -3.89 & 17.85 & -4.74 \\
\hline C-C & 1.09 & -0.91 & 1.97 & -1.69 & 4.09 & -1.71 \\
\hline
\end{tabular}

The results in Table 2 indicates that for low peak load values, the rebound of the structure is significant compared to the inbound displacement. The results obtained for the peak load value of $0.15 \mathrm{MN} / \mathrm{m}$, clearly indicate that the rebound displacements of the beam are higher than the inbound displacements for the simply supported case and also for the cases where springs were used to provide support flexibility. The results obtained for a peak load of $0.15 \mathrm{MN} / \mathrm{m}$, reinforce the previous findings for single degree of freedom (SDOF) models in previous section, where it was found that if rebound of the system occurs in a period of negative phase of the blast load, then this may lead to maximum displacement of the system due to the negative phase. Thus, the negative plastic deformations due to negative plastic forces may exceed in magnitude the positive plastic deformations caused by the larger forces of the triangular pulse.

The displacement-time history of the beam with simply supported conditions under a peak load of $0.15 \mathrm{MN} / \mathrm{m}$ is given in Figure 5 and the support reaction is given in Figure 6 . The figures show that the maximum support reaction is occurring with the maximum displacement at the rebound phase. The results in Table 2 shows that the blast loads with high peak pressure value increase the inbound displacements significantly and reduce the rebound displacements. Hence, the effect of the negative phase diminishes with the increase in peak pressure value. 


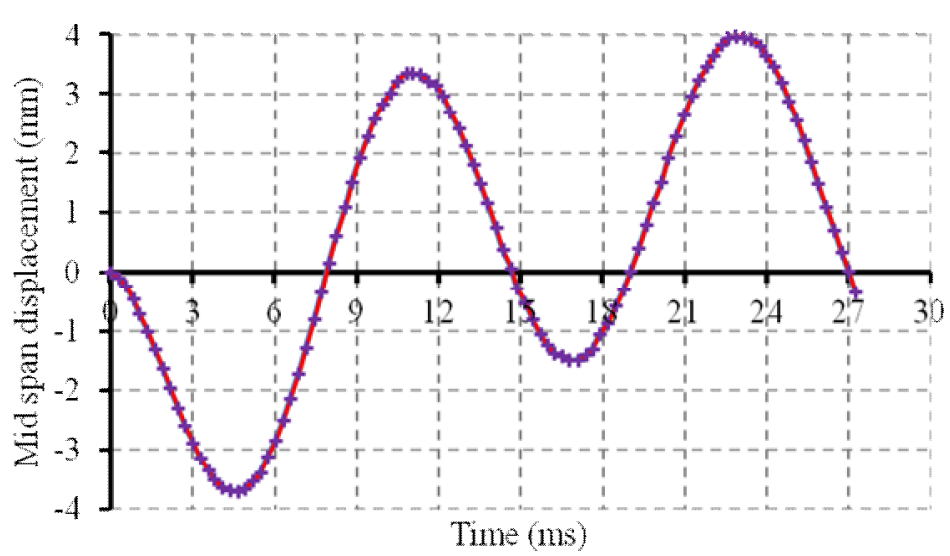

Figure 5. Mid-span deflection-time history of the simply supported beam under a blast load with a peak of $0.15 \mathrm{MN} / \mathrm{m}$ and duration of $8 \mathrm{~ms}$.

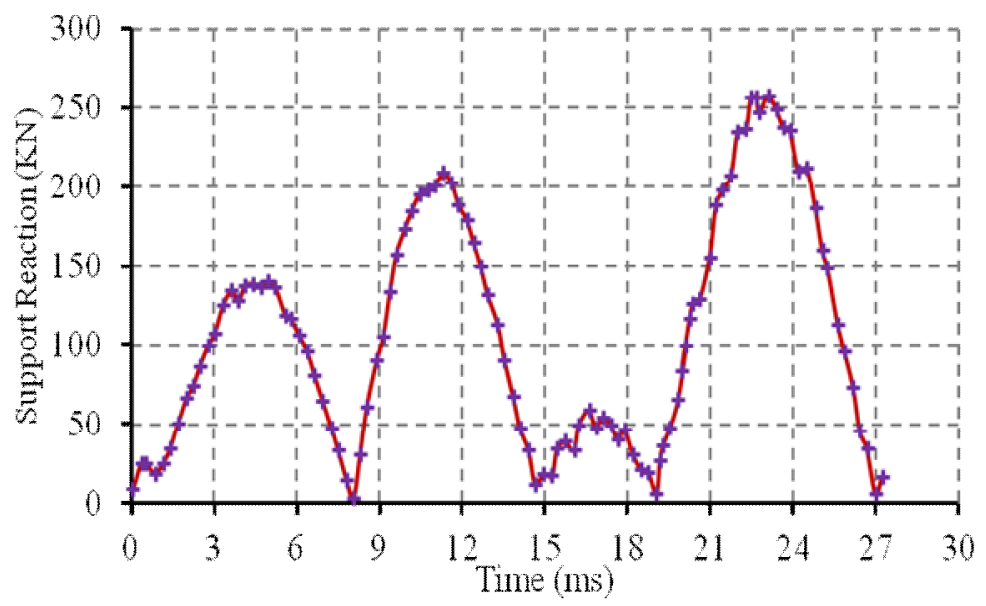

Figure 6. Support reaction-time history of the simply supported beam under a blast load with a peak of $0.15 \mathrm{MN} / \mathrm{m}$ and duration of $8 \mathrm{~ms}$.

The mid-span maximum displacements calculated for blast loads with the same peak pressure and positive phase duration, but with different values of waveform parameter of the modified Friedlander equation are given in Table 3. The results indicate that the negative phase has a significant effect when the blast waveform parameter is less than unity and becomes insignificant in contribution for the cases were that negative phase can be presented by the Friedlander equation with an $\alpha$-value larger than one.

Table 3. Summary of the responses calculated for loads with different amounts of the negative phase part for two support conditions.

\begin{tabular}{|c|c|c|c|c|c|c|}
\hline \multirow{3}{*}{$\begin{array}{c}\text { Support } \\
\text { condition } \\
\text { notation }\end{array}$} & \multicolumn{6}{|c|}{ Maximum mid-span deflection (mm) } \\
\hline & \multicolumn{2}{|c|}{$\begin{array}{l}\text { Waveform parameter } \\
\qquad \boldsymbol{\alpha}=\mathbf{0 . 7}\end{array}$} & \multicolumn{2}{|c|}{$\begin{array}{l}\text { Waveform parameter } \\
\qquad \alpha=1.0\end{array}$} & \multicolumn{2}{|c|}{$\begin{array}{c}\text { Waveform parameter } \\
\qquad \boldsymbol{\alpha}=\mathbf{2 . 0}\end{array}$} \\
\hline & Inbound & Rebound & Inbound & Rebound & Inbound & Rebound \\
\hline S-S & 3.70 & -3.97 & 3.70 & -3.51 & 3.70 & -3.19 \\
\hline $\mathrm{C}-\mathrm{C}$ & 1.09 & -0.91 & 1.09 & -0.89 & 1.09 & -0.66 \\
\hline
\end{tabular}




\section{Conclusion}

Effects of the negative phase of blast pressure curve on the structural response of RC elements were investigated. The effect of support flexibility on structural response under blast load with negative phase is also explored. Both SDOF analysis approach and detailed FE analysis was conducted. The study showed that when the negative phase of the blast loading was included in the analysis, no significant change was observed in the positive (inbound) displacement, but an increase in the negative (rebound) displacement was observed. It was also found that under low peak load, if the negative phase of blast load was considered, the rebound of the system could occur in a period of negative phase of the blast load, and then this would cause the maximum displacement to occur at rebound. However, the effect of negative phase of blast loading was found to be insignificant for beams with fixed support conditions. The flexibility of supports was found to increase the mid-span deflections when the support stiffness was lower than or close to the stiffness of the concrete element. The support stiffness was found to be insignificant to influence the overall structural response when the stiffness of support was few times higher than the stiffness of the concrete element.

\section{References}

[1] PDC-TR 08-07, Methodology Manual for Component Explosive Damage Assessment Workbook (CEDAW), Protective Design Center Technical Report, (2008).

[2] UFC 3-340-02, Structures to Resist the Effects of Accidental Explosions (Unified Facilities Criteria), US Department of Defense, (2008).

[3] PDC-TR 06-08, Single Degree of Freedom Structural Response Limits for Anti-terrorism Design: U.S. Army Corps of Engineers, (2008).

[4] C.J. Oswald and D. Skerhuf, FACEDAP User's Manual. Omaha District: U.S. Army Corps of Engineers, (1993).

[5] DIANA, User's Manual, Release 9.3. Delft, The Netherlands: TNO DIANA BV, (2008).

[6] G.F. Kinney and K.J. Graham, Explosive Shocks in Air, Springer, New York, (1985).

[7] A.C. Jacinto, R.D. Ambrosini and R.F. Danesi, Experimental and computational analysis of plates under air blast loading, Int. J. of Impact Engineering, 25(10), 927-947, (2001).

[8] C.M. Morison, Dynamic response of walls and slabs by single-degree-of-freedom analysis-A critical review and revision, Int. J. of Impact Engineering, 32, 1214, (2006).

[9] Mathworks, MATLAB Version 7.10 Natick, MathWorks, MA, (2010).

[10]A.K. Chopra, Dynamic of Structures: Theory and Applications to Earthquake Engineering, Pearson Prentice Hall, (2007).

[11]Z.I Syed, P. Mendis, N.T. Lam and T. Ngo, Concrete damage assessment for blast load using pressure-impulse diagrams, Proc. of Annual Technical Conference of the Australian Earthquake Engineering Society, Canberra, New Zealand, (2006).

[12]Z.I. Syed, P. Mendis, T. Ngo and N. Lam, Deflection Damage Criteria for Concrete Elements under Blast Loading Incorporating Sustainable Practice in Mechanics and Structures of Materials, CRC Press, 609-614, (2010).

[13]C.J. Gantes and N.G. Pnevmatikos, Elastic-plastic response spectra for exponential blast loading, Int. J. of Impact Engineering, 30(3), 323-343, (2004).

[14] J. Magnusson and M. Hallgren, Reinforced high strength concrete beams subjected to air blast loading, Structures and Materials, 15, 53-62, (2004).

[15]E. Thorenfeldt, A. Tomaszewicz and J.J. Jensen, Mechanical properties of high-strength concrete and applications in design, The Utilization of High-Strength Concrete, Stavanger, (1987).

[16]Elvira, Assessment of Progressive Collapse in Reinforced Concrete Frame Structures, PhD Thesis, The University of Melbourne, Melbourne, (2008).

[17]T. Ngo, Behaviour of High Strength Concrete Subject to Impulsive Loading, PhD Thesis, The University of Melbourne, Melbourne, (2005). 